\title{
In Response: New Controversial Diagnoses: Self-Defeating and Sadistic Personality Disorders
}

\author{
Frederic Kass, MD \\ Columbia University College of Physicians and Surgeons
}

Follow this and additional works at: https://jdc.jefferson.edu/jeffjpsychiatry

Part of the Psychiatry Commons

Let us know how access to this document benefits you

\section{Recommended Citation}

Kass, MD, Frederic (1987) "In Response: New Controversial Diagnoses: Self-Defeating and Sadistic Personality Disorders," Jefferson Journal of Psychiatry. Vol. 5 : Iss. 1 , Article 14.

DOI: https://doi.org/10.29046/JJP.005.1.010

Available at: https://jdc.jefferson.edu/jeffjpsychiatry/vol5/iss1/14

This Article is brought to you for free and open access by the Jefferson Digital Commons. The Jefferson Digital Commons is a service of Thomas Jefferson University's Center for Teaching and Learning (CTL). The Commons is a showcase for Jefferson books and journals, peer-reviewed scholarly publications, unique historical collections from the University archives, and teaching tools. The Jefferson Digital Commons allows researchers and interested readers anywhere in the world to learn about and keep up to date with Jefferson scholarship. This article has been accepted for inclusion in Jefferson Journal of Psychiatry by an authorized administrator of the Jefferson Digital Commons. For more information, please contact: JeffersonDigitalCommons@jefferson.edu. 


\title{
In Response:
}

\section{New Controversial Diagnoses: Self-Defeating and Sadistic Personality Disorders}

\author{
Frederic Kass, M.D.
}

Until several years ago the entire literature on Masochistic Personality was theoretical or anecdotal. Dr. Fuller's recent paper, "Masochistic Personality Disorder: A Diagnosis Under Consideration," is a timely contribution in that it is one of a growing number of empirical studies on this topic (1). His major finding, that Masochistic Personality describes a disorder which is not adequately described by the existing Axis II disorders, is consistent with data we recently reported (2). We have found, in addition, that the diagnosis is common, and that the criteria have good internal consistency, specificity, and sensitivity $(3,4)$. At this point the data compare favorably with what is available for the existing Axis II disorders.

Recently, feminists and others have pointed out that inclusion of the disorder in DSM-III-R could lead to stigmatization of women. The following three concerns have been articulated: 1) the historic association of the term masochistic with controversial psychoanalytic notions about female sexuality and the derivation of unconscious pleasure from suffering; 2) diagnoses such as Histrionic, Dependent, and Masochistic Personality Disorders represent males' stereotyped view of women; and 3) masochistic diagnostic criteria fail to discriminate between psychopathology and the adaptive patterns of victims, who are helpless and exploited. Furthermore, women suffer from socially reinforced pressure toward self-sacrifice and submission and do not have the avenues of escape which are open to men.

After considerable discussion and debate, the Assembly of the American Psychiatric Association recently approved the diagnosis for inclusion in DSM$I I I-R$ in an appendix (5). The name was changed to Self-Defeating Personality Disorder (SDPD), and the criteria were significantly altered (see Figure 1). An

\footnotetext{
Dr. Kass is Associate Chairman of the Department of Psychiatry, Columbia University's College of Physicians and Surgeons, and Deputy Director of Psychiatry at Presbyterian Hospital. He has participated in empirical work on Self-Defeating Personality and is a contributor to the formulation of criteria for this diagnostic category.
} 
effort was made to define a personality disorder which was distinct from stereotyped views of women and from syndromes of adaptive adjustment to victimization. The following clinical description was developed in collaboration with Drs. Roger MacKinnon and Robert Spitzer.

The essential feature of SDPD is a pervasive pattern of self-defeating behavior, beginning by early adulthood and present in a variety of contexts. The individual may often avoid or undermine pleasurable experiences, be drawn to situations or relationships in which he or she will suffer, and prevent others from helping him or her. The diagnosis is not made if the self-defeating behaviors only occur in situations in which the individual is responding to or anticipating being physically, sexually, or psychologically abused. Similarly, the diagnosis is not made if the self-defeating behaviors only occur when the individual is depressed.

Individuals with SDPD repeatedly enter into relationships or situations that are self-defeating and have painful consequences, and they do so even when better options are clearly available. For example, a person who repeatedly chooses to enter relationships with others who turn out to be alcoholics or who are in some way emotionally unavailable. They may continually enter employment situations where despite their excellent skills, their work is unrecognized and they are underpaid.

Reasonable offers of assistance from others are rejected. This may vary from repeated polite refusals of favors or gifts from others, to sabotage of helpful or nurturing efforts by others. For example, the individual may often loan money to friends but refuse to accept loans from others even when badly needed; he or she may fail to contact a physician when seriously ill. In the treatment situation, the individual fails to follow through on the agreed upon treatment plan.

Following positive personal events, such as graduation, a job promotion or raise, or any form of praise or encouragement from others, the individual responds with depression or a feeling of guilt. Following a positive event, the individual may do something that brings about pain, such as having an accident or losing something valuable.

Characteristically, individuals with this disorder act in such a way that causes others to be angry or reject them. For example, the individual may make fun of his or her spouse in public by belittling their capabilities, only to feel hurt later when the spouse retaliates. In treatment, the individual may make unreasonable requests for special attention and then feel rejected when the therapist refuses.

Opportunities for pleasure may be repeatedly avoided. For example, the individual may not take vacations, alternatively, he or she may participate in what most people would regard as an enjoyable activity, such as going to the movies or to a party, but deny having experienced any pleasure.

Individuals with SDPD report a number of situations in which they had the opportunity to accomplish a task crucial to their personal success, but despite 
having the capacity to complete the task, failed to do so. For example, the individual may have contributed excellent ideas to help a colleague complete a proposal, but fails to complete his own proposal.

People who consistently treat the individual well are often experienced as boring or uninteresting. Relationships with seemingly caring individuals are rejected or not pursued. These relationships may be personal, e.g., a needed potential therapist. Although the individual may describe stimulating sexual relationships with exploitative or insensitive partners, he or she may find caring partners sexually unattractive.

The individual frequently attempts to do things for others that require excessive self-sacrifice, even though these sacrifices are unsolicited by the intended recipients. The sacrifice does not make the individual feel better (as in the case of altruistic behavior that engenders a sense of pride and enhances the doer's self-esteem). Such sacrifice also has the effect of inducing guilt in others which often results in others avoiding or rejecting the individual.

In the discussions of Masochistic Personality, it was pointed out that none of the existing diagnoses adequately described the personality of many individuals who are chronic perpetrators of violence and abuse. In an effort to correct that deficiency, another new diagnosis, Sadistic Personality Disorder, has been approved for inclusion in the DSM-III-R Appendix (see Figure 2). The Sadistic criteria describe a pervasive pattern of cruel, demeaning and aggressive behavior directed towards other people, beginning by early adulthood. The sadistic behavior is often evident both in social relationships and at work (with subordinates); the diagnosis is not made if the behavior has been directed toward only one person (e.g., a spouse). The diagnosis is also not made if the sadistic behavior has been only for the purpose of sexual arousal (as in Sexual Sadism).

It is hoped that by developing operational criteria for Self-Defeating and Sadistic Personality Disorders, new clinical research will be catalyzed which will shed light on questions which remain with regard to the reliability and validity of these categories.

FIGURE 1

Diagnostic Criteria for Self-Defeating Personality Disorder

A. A pervasive pattern of self-defeating behavior, beginning by early adulthood and present in a variety of contexts. The individual may often avoid or undermine pleasurable experiences, be drawn to situations or relationships in which he or she will suffer, and prevent others from helping him or her, as indicated by at least five of the following:

(1) Chooses persons and situations that lead to his or her disappointment, failure or mistreatment even when better options are clearly available to him or her

(2) Rejects or renders ineffective the attempts of others to help him or her

(3) Following positive personal events (e.g., new achievement), responds with depression, guilt, or a behavior that brings about pain (e.g., an accident) 
(4) Incites angry or rejecting responses from others and then feels hurt, defeated or humiliated (e.g., makes fun of spouse in public, provoking an angry retort, then feels devastated)

(5) Turns down opportunities for pleasure, or is reluctant to acknowledge enjoying himself or herself (despite having adequate social skills and the capacity for pleasure)

(6) Fails to accomplish tasks crucial to his or her personal objectives despite demonstrated ability to do so (e.g., helps fellow students write papers, but is unable to write his or her own)

(7) Is uninterested in or rejects people who consistently treat him or her well (e.g., is unattracted to caring sexual partners)

(8) Engages in excessive self-sacrifice that is unsolicited by the intended recipients of the sacrifice

B. The behaviors in A do not occur only in response to, or in anticipation of, being physically, sexually or psychologically abused.

C. The behaviors in A do not occur only when the individual is depressed.

FIGURE 2

Diagnostic Criteria for

Sadistic Personality Disorder

A. A pervasive pattern of cruel, demeaning and aggressive behavior, beginning by early adulthood, as indicated by the repeated occurrence of at least four of the following:

(1) Has used physical cruelty or violence for the purpose of establishing dominance in a relationship (not merely to achieve some non-interpersonal goal, such as mugging someone in order to steal)

(2) Humiliates or demeans people in front of others

(3) Has treated or disciplined someone under his or her control unusually harshly (e.g., a child, student, prisoner or patient)

(4) Is amused by or takes pleasure in the psychological or physical suffering of others (including animals)

(5) Has lied for the purpose of harming or inflicting pain on others (not merely to achieve some other goal)

(6) Gets other people to do what he or she wants by frightening them (from intimidation to terror)

(7) Restricts the autonomy of people with whom he or she has a close relationship (e.g., won't let spouse out of the house unaccompanied, won't let teenage daughter attend school dances)

(8) Is fascinated by violence, weapons, martial arts, injury or torture

B. The behavior in A has not been directed toward only one person (e.g., spouse, one child) and has not been only for the purpose of sexual arousal (as in Sexual Sadism)

\section{REFERENCES}

1. Fuller AK: Masochistic personality disorder: a diagnosis under consideration. Jefferson Journal of Psychiatry 2:7-21, 1986 
2. Kass F, MacKinnon RA, Spitzer RL: Masochistic personality: an empirical study. Am J Psychiatry 143:216-218, 1986

3. National field trial on self-defeating personality disorder. (unpublished data)

4. Kass F: Self-defeating personality disorder: an empirical study. Journal of Personality Disorders (in press)

5. American Psychiatric Association; Diagnostic and Statistical Manual of Mental Disorders, Revised Third Edition, Washington, DC, APA, 1987 